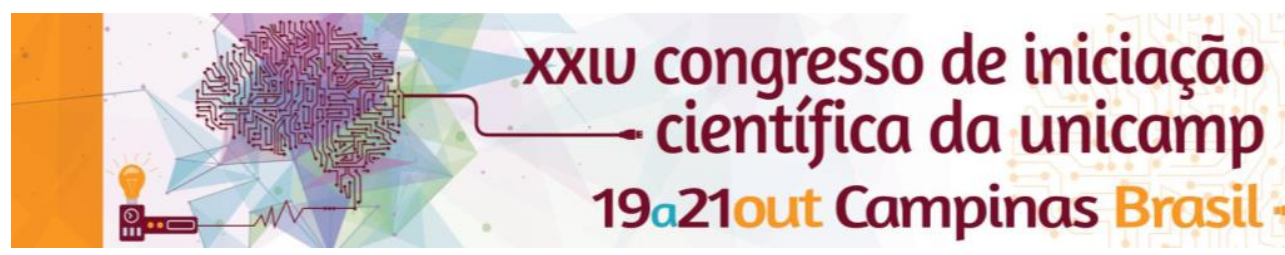

\title{
Análise de impacto de balas de borracha em um modelo computacional de olho humano.
}

\section{Gabriela R. Correa*, Marco L. Bittencourt}

\section{Resumo}

Este projeto tem como objetivo estudar os danos causados pelo impacto de um projétil de borracha ao olho humano, tendo como principal lesão o possível descolamento da retina. Esta análise foi feita através da simulação computacional deste impacto utilizando o programa ABAQUS, no qual os materiais que constituem o globo ocular e o projétil de borracha foram estudados $\mathrm{e}$ caracterizados para a sua modelagem.

\section{Palavras-chave \\ Modelagem, simulação, MEF.}

\section{Introdução}

O impacto de um objeto contra o olho causa danos diretos no local em que foi atingido e também danos indiretos a tecidos oculares mais distantes devido à transmissão de forças [1].

Esses traumas podem levar ao descolamento da retina, fato que ocorre quando há o seu desprendimento da coróide, e a consequente não vascularização nas células da retina, deixando-as sem oxigênio e nutrientes. Se não tratada, esta condição pode levar à degeneração celular e resultar na perda da visão [2].

O objetivo deste projeto é estudar casos de impacto de balas de borracha em um modelo de olho humano, com - auxílio do programa comercial ABAQUS ${ }^{8} \mathrm{CAE}$ (Computer Aided Engineering).

\section{Resultados e Discussão}

Para o desenvolvimento do projeto foi utilizado o modelo mostrado na Figura 1 desenvolvido por [3], o qual envolve as seguintes estruturas: retina, corpo ciliar, fibras zonulares, lente, esclera e a córnea. Os materiais e respectivos parâmetros das estruturas citadas estão definidos na literatura, com excessão dos dois últimos. Os parâmetros da esclera e da córnea, materiais hiperelásticos, foram calculados partindo-se de um gráfico de tensãoxdeformação [1].

Através do estudo da simulação de tal modelo ao sofrer um impacto com um projétil de borracha utilizando o programa ABAQUS $\AA$ através do Método dos Elementos Finitos foi possível qualitizar o dano à qual um indivíduo está exposto nesta situação. A simulação dinâmica nãolinear ocorreu com três diferentes velocidades de impacto, sendo essas inferiores à real velocidade de impacto.

A análise dos resultados permitiu inferir que as tensões e o deslocamento nas partes que constituem o olho aumentam com o aumento da velocidade do projétil.

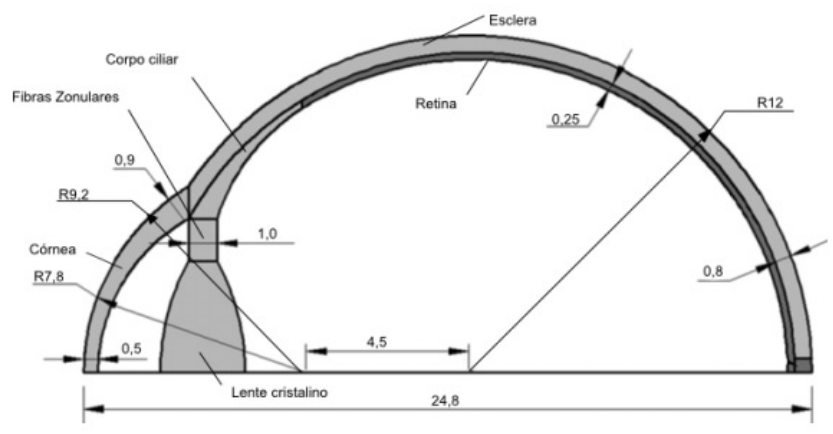

Figura 1. Estruturas e dimensões do modelo abordado. Adaptado de [3].

\section{Conclusões}

Como visto, o projeto alcançou o objetivo de modelar o problema em questão e simulá-lo para provar que tal impacto ocasionará danos ao olho humano. Devido a problemas de convergência na simulação, não foi possível obter dados numéricos para velocidades próximas a real do projétil, sendo esse o objetivo para um próximo trabalho.

\section{Agradecimentos}

Gostaria de agradecer ao Prof. Dr. Marco Lucio Bittencourt e ao Doutorando Jorge Suzuki pela ajuda durante todo o decorrer do projeto. Agradeço também ao $\mathrm{CNPq}$ - Conselho Nacional de desenvolvimento científico e tecnológico pela concessão da bolsa de iniciação científica.

\footnotetext{
${ }^{1}$ JOHNSTON, P.B.,'Traumatic retinal detachment". British Journal of Ophthalmology, Vol 75, n.1, pp 18-21. 1991
} 